\title{
PENGARUH KONSEP DIRI TERHADAP PRILAKU ASERTIF MAHASISWA STKIP BUDI DAYA BINJAI
}

\author{
Deva Friani dan Nurul Hasanah \\ Penulis adalah Dosen Sekolah Tinggi Keguruan dan Ilmu Pendidikan (STKIP) \\ Perguruan Tinggi Budidaya Binjai
}

\begin{abstract}
Assertive behavior is an ability to communicate what they want, feel, and think to others while maintaining and respecting the rights and feelings other people. the concept of self is something in yourself that people have about themselves in shape with confidence, persaan or attitude of a person through the experiences he gained from interaction with the environment. A positive self concept will bring a person to be assertive, so that when interacting with a positive environmental and insightful it will form a positive self-concept, and vice versa. This type of research is quantitative research. This study aims to determine how big the influence of self-concept toward assertive behavior STKIP Raising student Binjai. The problem in this research are: 1). Is there any influence on the behavior of self-concept of students STKIP Cultivation asrtif Binjai ?. This Penelitain use of hypothesis testing. The population in this study were students smester 5 totaling 250 people. Samples taken as many as $20 \%$ of the population, as many as 50 people. Data retrieved through a questionnaire of selfconcept and assertive behavior, as many as 80 items before the trial and after the trial 67 items. Data analysis using test engineering requirements analysis, and hypothesis testing ANOVA one way. Based on the research that has been done, the conclusion: there is the influence mkionsep themselves against the assertive behavior STKIP Raising student Binjai. Gasil coefficient of $0.002 \mathrm{P}$-value is greater than the significance level of 0.05 , when the P-valuevlue less than 0.05then declared to have significance. So the results of the analysis ofcoefficient the P-vlue smaller than it otherwise there is a significant level of self-concept influences on behavior influence of student assertive STKIP Cultivation Binjai. Suggestions for further research to be researched and developed with the same topic, is expected to make a more specific measurement tools and simpler language so easy to understand students. In addition to improving the correlation between the factors of each instrument of research, may be created or designed a better measuring devices.
\end{abstract}

Keywords: Self-concept, Assertive Behavior.

\section{PENDAHULUAN}

Masa dewasa awal adalah suatu priode transisi dari masa awal anak hingga masa awal dewasa, yang dimasuki pada usia kira kira pada 18 tahun hingga 25 tahun. Pada fase ini, usia dewasa awal menunjukan prilaku dan pribadi untuk mengeksprolasi berbagai gaya hidup nilai - nilai yang secara intlektual dan peran sosial. Istilah adult atau dewasa berasal dari kata latin yang berarti tumbuh atau tumbuh menjadi dewasa. Pada masa dewasa kebutuhan untuk didengar dan diakui menjadi semakin besar. 
Namun di sisi lain, tuntutan lingkungan sosial yang besar terhadap diri remaja seringkali berbenturan dengan kebutuhan dalam diri remaja tersebut. Konflik berupa tuntutan dan lingkungan dengan kebutuhan dalam diri remaja kan menimbulkan emosi emosi negatif ${ }^{1}$.

Mahasiwa dengan asertif yang tinggi akan mampu menggungkapkan kebutuhan-kebutuhan dalam dirinya sekaligus dapt mengekspresikan emosi dan perasaanya melalui cara yang tepat sehingga lingkungan pun akan memahaminya. Apabila seorang mahasiswa yang tidak memiliki sikap yang asertif, maka mahasiswa tersebut akan memilih untuk diam tanpa mengutarakan persaan dan pikirannya pada orang lain, dan cenderung untuk memenuhi tuntutan lingkungan dengan menekan kebutuhan dirinya maka akan menimbulkan ketangangan dan perasaan yang tidak nyaman akibat menahan dan menyimpan sesuatu yang ingin diutarakanya ${ }^{2}$. Asertif adalah suatu cara untuk mengkomunikasikan ide-ide, kebutuhan, keinginan dan niat dengan cara yang jelas dan percaya diri, dan untuk melakukan hal ini, sesuatu yang dilakukan tanpa bermusuhan atau terlalu menuntut.

Kelebihan dari prilaku asertif yaitu, bebasnya seseorang dari konflik internal, meningkatkan kepercayaan diri, membantu mengelola stress, hidup yang terikat tidak dan bebas. Sedangkan kekurangan pada prilaku asertif ini adalah seseorang lebih memilih untuk diam tanpa mengutarakan perasaan dan pikirannya pada orang lain, dan cenderung untuk memenuhi tuntutan lingkungan dengan menekan kebutuhan dirinya maka akan menimbulkan ketangangan dan perasaan yang tidak nyaman akibat menahan dan menyimpan sesuatu yang ingin diutarakanya. Menurut Wuryanano faktor faktor yang mempengaruhi konsep diri yaitu, cita-cita diri yang bearti keinginan untuk mencapai sesuatu tujuan dan keinginan pribadi, hal ini sangat dipengaruhi oleh lingkungan sekitar, orang tua, teman ataupun tetangga, citra diri merupakan suatu produk dari pengalaman masa lalu beserta sukses dan kegagalannya, harga diri merupakan suatu penghargaan kepada diri sendiri yang berarti menentukan seberapa tinggi harga diri seseorang.

Konsep diri merupakan apek penting dalam diri seseorang, karena konsep diri merupakan kerangka acuan (frame dan reference) dalam berinteraksi dengan lingkungan. Dalam kehidupan sehari-hari konsep diri berperan penting pada setiap

\footnotetext{
${ }^{1}$ Desmita, Psikologi Perkembangan. Bandung: Remaja Rosda Karya

${ }^{2}$ Townend, Developing Assertiveness ( Self Development For managres). London: Routledge.
} 
individu sehingga menentukan perilakunya dalam berinteraksi dengan lingkungan. Bagaimana individu memandang diri, akan nampak dari seluruh perilaku.

Konsep diri juga sebetulnya terbentuk berdasarkan persepsi seseorang dengan berbagai sikap sikap orang lain terhadap dirinya. Pada seseorang mahasiswa, ia mulai belajar berfikir dan merasakan dirinya seperti apa yang telah ditentukan oleh orang lain dalam lingkungannya, misalnya, orang tuanya, dosenya, ataupun teman-temanya. Berdasarkan hasil penelitian yang diperoleh bahwa hasil subjek mahasiswa STKIP Budi Daya Binjai memiliki tingkat prilaku asertif yang cenderung tinggi, rentang subjek berkisar antara usia 18 - 21 tahun. Yang jumlah subjeknya berusia 18 tahun yang berjumlah 12 orang, jumlah subjek yang berusia 19 tahun yang berjumlah 12 orang, jumlah subjeknya berusia 20 tahun yang berjumlah 10 orang, sedangkan jumlah subjeknya berusia 21 tahun yang berjumlah 6 orang.

Dari hasil penelitian yang didapatkan subjek yang berjenis kelamin laki laki berjumlah 17 orang. Sedangkan subjek perempuan berjumlah 23 orang. Berdasarkan hasil deskripsi diketahui bahwa subjek yang berjenis kelamin laki laki cenderung lebih asertif dibandingkan dengan subjek prempuan, begitu pula dalam kepercayaan diri. Subjek yang berjenis kelamin laki laki cenderung lebih percaya diri di bandingkan dengan subjek perempuan. Berdasarkan dari tingkat perkuliahan mahasiswa tingkat 1 dan dan 5 cenderung lebih aserif dibandingkan mahasiswa tingkat 2, 3 dan 4. Akan tetapi tingkat pada kepercayaan diri mahasiswa tingkat 5 yang cenderung lebih tinggi dibandingkan dengan tingkat 1, 2, 3, dan 4. Berdasarkan latarbelakang masalah di atas, maka penulis tertarik untuk meneliti tentang: Pengaruh Konsep Diri terhadap Prilaku Asertif Mahasiswa STKIP Budi Daya Binjai.

\section{METODOLOGI PENELITIAN}

\section{A. Lokasi}

Penelitian ini akan dilaksanakan di STKIP Budi Daya Binjai. Alamat Jln. Gaharu No. 147, Jati makmur Kota Binjai. Alasan saya meneliti lokasi di STKIP Budi Daya Binjai ini adalah untuk mengetahui pengolahan dan penafsiran dalam bentuk data dan keterangan yang berkaitan dengan apa yang menjadi tujuan dalam meneliti.

\section{B. Waktu Penelitian}

Penelitian ini akan dilaksanakan pada bulan Agustus sampai bulan Juli 2017. 


\section{Desain Penelitian}

Penelitian kuantitatif adalah penelitian ilmiah yang sistematis terhadap bagianbagian dan fenomena serta hubungan-hubungannya. Tujuan penelitian kuantitatif adalah mengembangkan dan menggunakan model-model matematis, teori-teori dan/atau hipotesis yang berkaitan dengan fenomena alam.

Teori merupakan suatu kumpulan konsep (concept), definisi, proposisi dan variabel yang keterkaitan antara satu sama lain secara sistematis dan telah digeneralisasikan, sehingga dapat menjelaskan dan mempredeksi fenomena (faktafakta) tertentu. Suatu teori berguna untuk mendefinisikan suatu masalah yang didalamnya ada variabel-variabel tertentu,untuk mengartikan data dan fenomenafenomena yang ditemukan seperti ${ }^{3}$.

Ciri-ciri utama penelitian kuantitatif ini adalah:

1. Permasalahan dalam penelitian terbatas dan sempit

2. Memiliki pola berpikir deduktif

3. Mempercayai angka (statistika atau matematika) sebagai instrumen untuk menjelaskan kebenran.

4. Membangun validitas internal dan validitas eksternal sebaik mungkin.

\section{Definisi Operasional}

Agar penjelasan variabel pada penelitian ini tidak menyimpang dari batasan teori yang dibahas, maka di jelaskan istilah yang dimaksudkan dalam penelitian ini yaitu variabel:

1. Konsep Diri: Konsep diri yang dimaksudkan dalam penelitian ini adalah pengetahuan, penilaian, dan harapan mahasiswa tentang dirinya dan lingkungannya. Konsep diri di ukur dengan menggunakan skala konsep diri menurut Hurlock yang terdiri dari: Perceptual, Conceptual, Attitudinal. ${ }^{4}$

2. Perilaku Asertif: Prilaku asertif yang dimaksudkan dalam penelitian ini adalah bagaimana cara individu dalam memberikan respon dalam situasi sosial, yang berarti sebagai kemampuan individu untuk mengatakan tidak, kemampuan untuk menanyakan dan meminta sesuatu, kemampuan untuk mengungkapkan perasaan positif ataupun negatif, serta kemampuan untuk mengawali kemudian

\footnotetext{
${ }^{3}$ Sugiyono, Metode Penelitian Kuantitatif, Kualitatif, dan $R \&$ D. Bandung: Alfabeta , 2008 )

${ }^{4}$ Hurlock, Psikologi fase-fase perkembangan manusia umum.
} 
melanjutkan serta mengakhiri percakapan. Prilaku asertif di ukur dengan menggunakan skala prilaku asertif menurut Lazarus dalam Rakos ${ }^{5}$ yang terdiri dari: Kepribadian, Jenis Kelamin, Sikap Orang Tua, Pendidikan, Kebudayaan.

\section{E. Populasi}

Populasi dalam penelitian ini adalah seluruh Mahasiswa STKIP Budi Daya Binjai, dengan jumlah mahasiswa 250 orang yang terdiri dari 6 kelas.

\begin{tabular}{|c|c|}
\hline SMESTER V & JUMLAH \\
\hline AP & 9 \\
\hline BK & 41 \\
\hline PBI & 40 \\
\hline PBSID & 76 \\
\hline PPKN & 34 \\
\hline PM & 50 \\
\hline JUMLAH : & 250 Mahasiswa \\
\hline
\end{tabular}

\section{F. Sampel Penelitian}

Sampel dalam penelitian ini adalah Mahasiswa STKIP Budi Daya Binjai. Dikarenakan jumlah populasi yang tidak terlalu banyak, maka peneliti memutuskan untuk mengambil seluruh populasi mahasiswa smester IV untuk dijadikan sebagai sampel yang berjumlah 250 mahasiswa. Sampel dalam penelitian ini berkisar $20 \%$ atau 50 Mahasiswa.

\section{G. Teknik Sampling}

Teknik sampling yang digunakan dalam penelitian ini adalah teknik sampling Probabilistic. Dikarenakan jumlah populasi yang tidak terlalu banyak, yang hanya berjumlah 250 mahasiswa, sehingga peneliti memutuskan untuk menjadikan seluruh populasi sebagai sampel.

\section{H. Instrumen Penelitian.}

Instrumen penelitian ini adalah alat bantu yang digunakan oleh peneliti untuk mengumpulkan informasi tentang variabel atau objek yang sedang diteliti. Instrumen 
pengumpulan data adalah alat bantu yang dipilih dan digunakan oleh peneliti dalam kegiatannya mengumpulkan agara kegiatan tersebut menjadi sistematis dan dipermudah olehnya menurut Arikunto.

\section{Alat Ukur penelitian}

Alat yang digunakan untuk mengumpulakan data primer dalam penelitian ini adalah kuesioner. Peneliti menggunakan kuesioner yang dikembangkan oleh Delgado dan Munuera (2005). Skala yang digunakan dalam penelitian ini adalah skala likert. Skala ini berinterasi 1-5 dengan pilihan jawaban sebagai berikut : (1) Sangat Tidak Setuju (STS), (2) Tidak Setuju (TS), (3) Netral (N), (4) Setuju (S), (5) Sangat Setuju (SS). Pemberian skor untuk masing-masing jawaban dalam kuesioner adalah sebagai berikut : Pilihan pertama, memiliki nilai skor 1 (Satu), Pilihan kedua, memiliki nilai skor 2 (dua), pilihan ketiga, memiliki nilai skor 3 (tiga), Pilihan keempat, memiliki nilai Skor 4 (empat), pilihan kelima, memiliki nilai skor 5 (lima).

Tabel 3.1.

Blueprint Prilaku Asertif (Variabel Y)

\begin{tabular}{|l|l|l|l|c|}
\hline NO & \multicolumn{1}{|c|}{ Aspek } & \multicolumn{1}{|c|}{ Fovorable } & Unfovorable & Jumlah \\
\hline 1 & $\begin{array}{l}\text { Berusaha Mencapai } \\
\text { Tujuan }\end{array}$ & $1,7,11,21,32,40$ & 3,10 & 8 \\
\hline 2 & Pengungkapan Diri & $6,4,12,17,35,39$ & 8,9 & 8 \\
\hline 3 & $\begin{array}{l}\text { Menghormati dan tidak } \\
\text { mengganggu hak orang } \\
\text { lain }\end{array}$ & $5,13,15,18,31,37$ & 14,16 & 8 \\
\hline 4 & Jujur dan terbuka & $2,19,23,34,36,38$ & 20,22 & 8 \\
\hline 5 & Penolakan & $24,26,27,28,30,33$ & 29,25 & 40 \\
\hline
\end{tabular}

Untuk memperoleh data yang diperlukan dalam penelitian ini, penelitian ini menggunakan alat ukur skala. Skala yang digunakan untuk mengumpulkan data adalah skala komunikasi yang peneliti buat berdasarkan ciri-ciri konsep diri , Skala konsep terdiri dari 5 item . Adapun format yang digunakan dalam alam skala psikologi (instrumen penelitian) ini terdiri dari 5 alternatif jawaba yaitu 
dengan kriteria jawaban sangat setuju (SS), setuju (S), netral (N), ttidak setuju (TS), dan sangat tidak setuju (STS).

\section{a. Validitas}

Validitas adalah suatu derajat ketepatan/kelayakan instrument yang digunakan mengukur apa yang akan diukur (Zainal Arifin.2012). Untuk melakukan uji validitas ini menggunakan program SPSS.

Analisis ini dengan cara mengkorelasikan masing-masing skor item dengan skor total. Dari hasil uji validitas skala asertif dari 40 skala yang di uji terdapat 7 aitem yang tidak valid artinya $\mathrm{P}<0,25$. sedangkan skala konsep diri dari 40 aitem yang diujikan terdapat 6 aitem yang tidak valid.

\section{J. Teknik Analisis Data}

\section{a. Normalitas}

Uji normalitas digunakan untuk mengetahui apakah populasi data berdistribusi normal atau tidak. Uji ini biasanya digunakan untuk mengukur data berskala ordinal, interval, ataupun rasio.

\section{b. Linearitas}

Uji linearitas bertujuan untuk mengetahui apakah dua variabel mempunyai hubungan yang linear atau tidak secara signifikan. Uji ini biasanya digunkan sebagai prasyarat dalam analisis korelasi atau regresi linear.

\section{c. Uji Hipotesis}

Uji hipotesis adalah metode pengambilan keputusan yang didasarkan dari analisis data, baik dari percobaan yang terkontrol, maupun dari observasi tidak terkontrol.

\section{HASIL DAN PEMBAHASAN PENELITIAN}

\section{Subjek Penelitian}

Deskripsi subjek penelitrian dilakukan dengan tujuan agar mengetahui Pengaruh Konsep Diri terhadap prilaku asertif mahasiswa STKIP Budi Daya Binjai.

\begin{tabular}{|c|l|c|c|}
\hline No. & \multicolumn{1}{|c|}{ Jenis Kelamin } & Jumlah & Persen \% \\
\hline 1 & Laki - laki & 10 & $60 \%$ \\
\hline 2 & Perempuan & 15 & $40 \%$ \\
\hline \multicolumn{2}{|c|}{ JUMLAH } & $\mathbf{2 5}$ & $100 \%$ \\
\hline
\end{tabular}




\section{Uji Standart Normalitas}

Uji Normalitas dilakukan untuk mengetahui apakah distribusi data penelitian setiap variabel telah menyebar secara normal. Uji normalitas dilakukan dengan metode statistik menggunakan program SPSS version 21.0.

\section{Uji linearitas}

One-Sample Kolmogorov-Smirnov Test

\begin{tabular}{|ll|r|r|}
\hline & & \multicolumn{1}{|c|}{ konsepdiri } & \multicolumn{1}{c|}{ Asertif } \\
\hline N & & 50 & 50 \\
& Mean & 104,48 & 100,16 \\
& Std. Deviation & 14,726 & 14,988 \\
Most Extreme Differences & Absolute &, 154 &, 129 \\
& Positive &, 078 &, 069 \\
Kolmogorov-Smirnov Z & Negative &,- 154 &,- 129 \\
Asymp. Sig. (2-tailed) & & 1,092 &, 909 \\
& &, 184 &, 380 \\
\hline
\end{tabular}

Berdasarkan pada table diatas dapat dilihat nilai variable konsep diri terdistribusi secara normal dengan nilai $\mathrm{P}>0,05(0,184>0,05)$.

ANOVA Table

\begin{tabular}{|c|c|c|c|c|c|c|c|}
\hline & & & $\begin{array}{l}\text { Sum of } \\
\text { Squares }\end{array}$ & df & $\begin{array}{l}\text { Mean } \\
\text { Square }\end{array}$ & $\mathrm{F}$ & Sig. \\
\hline & & (Combined) & 8181,897 & 19 & 430,626 & 5,285 & ,000 \\
\hline & & Linearity & 87,998 & 1 & 87,998 & 1,080 & ,307 \\
\hline & Detween & Deviation & & & & & \\
\hline homptomi & & from & 8093,899 & 18 & 449,661 & 5,518 & ,000 \\
\hline ASEIUI & & Linearity & & & & & \\
\hline & Within G & ups & 2444,583 & 30 & 81,486 & & \\
\hline & Total & & 10626,480 & 49 & & & \\
\hline
\end{tabular}

\section{A. Hasil penelitian}




\section{Hasil penelitian dilakukukan untuk menguji hipotesis penelitian yang mana hipotesis penelitian adalah :}

Ho: Tidak ada pengaruh yang tinggi/rendah konsep diri terhadap prilaku asertif mahasiswa STKIP Budi Daya Binjai.

Ha: Ada pengaruh yang tinggi/rendah konsep diri terhadap prilaku asertif mahasiswa STKIP Budi Daya Binjai.

\section{Correlations}

\begin{tabular}{|ll|r|r|}
\hline & & $\begin{array}{r}\text { Konsep } \\
\text { diri }\end{array}$ & Asertif \\
\hline konsepd & Correlation & 1 &, 091 \\
iri & Sig. (2-tailed) & &, 002 \\
& N & 50 & 50 \\
& Pearson &, 091 & 1 \\
Asertif & Correlation & & \\
& Sig. (2-tailed) &, 002 & \\
& N & 50 & 50 \\
\hline
\end{tabular}

Dari tabel diatas dapat diketahui bahwa nilai korelasinya adalah 0.002 yang P>0.05 Maka yang artinya Ho diterima yang bahwa terdapat pengaruh konsep diri terhadap perilaku asertif.

\section{HASIL PEMBAHASAN}

Hasil penelitian pengaruh konsep diri terhadap perilaku asertif Mahasiswa STKIP Budi Daya Binjai Adalah P > 0.002 yang mana terdapat pengaruh konsep diri terhadap perilaku asertif. Penelitian adalah uraian tentang hal-hal yang berkaitan dengan proses kegiatan penelitian (arikunto, 1995:600), oleh karena itu isi laporan penelitian bukan hanya langkah-langkah yang telah di lakukan oleh peneliti saja. Hasil penelitian dilakukukan untuk menguji hipotesis penelitian yang mana hipotesis penelitian adalah : 
Ho: Tidak ada pengaruh yang tinggi/rendah konsep diri terhadap prilaku asertif mahasiswa STKIP Budi Daya Binjai.

Ha: Ada pengaruh yang tinggi/rendah konsep diri terhadap prilaku asertif mahasiswa STKIP Budi Daya Binjai.

\section{KESIMPULAN}

Berdasarkan kajian teori dan hasil analisis serta mengacu pada perumusan masalah yang telah diuraikan bahwa hasil dari uji tersebut adalah 0,002 yaitu lebih kecil dari taraf signifikansi 0,05 yang artinya kedua variabel berhubungan secara signifikan, dapat ditarik kesimpulan sebagai berikut: Terdapat Pengaruh Konsep Diri Terhadap Perilaku Asertif Mahasiswa STKIP Budi Daya Binjai.

\section{DAFTAR PUSTAKA}

Atmosoeprapto, Krisdarto, 2002. Мепијu SDM berdaya-Dengan Kepemimpinan Efektif dan Manajemen Efisien. PT.Elex Media Komputindo: Jakarta

Alberti dan Emmons, Your Perpect Right: Panduan Prkatis Hidup Lebih Ekspresif Dan Jujur Pada Diri Sendiri. (Jakarta: Elex Media Komputindo, 2002)

Allport, Psikologi Kepribadian (Jakarta: Rajawali, 2003)

Burns, R.B.1993, Konsep Diri: Teori, Pengukuran, Perkembangan dan Prilaku. Jakarta: Penerbit Arcan

Bidulp, Teori Perkembangan Kepribadian (Jakarta: Erlangga,2003)

Callhoun dan Acocella, Pembentukan Kepribadian Anak, (Jakarta: PT. Gramedia, 2010)

Desmita 2005, Psikologi Perkembangan. Bandung: Remaja Rosda Karya

Gunarsa, Psikologi Perkembangan Anak dan Remaja. (Jakarta: BPK Gunung Mulia 2008)

Fukuyuma dan Greenfield, Psikologi Kepribadian(Jakarta: Raja Grafindo Pesarda, 2001)

Hadi, Metode Penelitian Pendidikan. (Jakarta: PT Rineka Cipta, 2002), hlm 110

Hendra Surya, Percaya Diri itu Penting: Peran Orangtua dalam Membutuhkan Percaya DiriAnak. Jakarta: Elex Media Komputindo, 2007)

Hurlock, Psikologi Perkembangan: Suatu Pendekatan Sepanjang Rentang Kehidupan, (Jakarta: Erlangga 2007) 
Hurlock, (1992) Psikologi Fase-fase Perkembangan Manusia Umum

Joan Rais, Singgih D Yulia, Psikologi Perkembangan Anak dan Remaja. (Jakarta: Bpk Gunung Mulia, 2008)

Kingsley, J. 2011. Developmental Assesment Of The Scholl - Age Child With Developmental Disabilities. Lodon: Thambirajah Lazarus (dlm Rakos, 1990) Margono. Metodologi Penelitian Pendidikan. (Jakarta: Rineka Cipta, 2010), hlm 118

Musthofa Fahmi, Penyesuaian Diri, terj. Zakiyah Drajat, (Jakarta: Bulan Bintang 2006),Hlm. 111

Pudjijogyanti, R. C. 1993. Konsep Diri dalam Pendidikan. Jakarta: Penerbit Arcan

Rakos, R.F. 1991. Assertive Behavior Theory, Research and Training. London: Routledge

Rathus dan Nevid, Adjustmen And Growth: The Of Life. New York: CBS College Publising.

Rini, Prilaku Asertif. Http:// www. E-PSIKOLOGI.com

Santrock, Evaluasi Spesifik Remaja (Jakarta: Erlangga, 2003)

Santrock, Jhon W, Adolescence: Perkenbangan Remaja. Terjemahan Shinto B Adelar dan Sherly Saragih, (Jakarta: Erlangga, 2003)

Sugiyono, Metode Penelitian Kuantitatif, Kualitatif, dan $R \& D$. Bandung Alfabeta, 2008)

Suharsimi Arikunto. Prosedur Penelitian, (Jakarta: PT Rineka Cipta, 2000), hlm 134.

Townend 1991, Developing Assertiveness (Self Development For Managres). London: Routledge

Wils dan Daisley, The Assertive Trainer: A Practical Handbook Assertiveness Of Trainers and Running Assertiveness Course. USA: Mc Graw Hill 